\title{
Core Serial Titles in an Interdisciplinary Field: The Case of Environmental Geology
}

\section{Louise S. Zipp}

\begin{abstract}
In this study core journals in environmental geology are identified and some facets of interdisciplinarity are explored to consider the visibility of this field to collection development librarians. Intercitation analysis of citing and cited patterns in 1995 articles revealed the journal network of environmental geology. The titles clustered into discrete groups with three emphases: Engineering/Materials; Geochemical; and Water/Soil. Most of the 20 core titles are usually identified with other disciplines and subfields. Research libraries supporting collections in environmental chemistry, hydrology, agronomy, and civil engineering might be effectively supporting serial collections in environmental geology. The scope of the field, however, is not inherently visible to collection development librarians whose attention is drawn to established disciplines by way of acquisition fund allocation models. Recent discussions on interdisciplinarity suggest that the characteristics of maturing disciplines, such as a unique body of publications, academic infrastructure, and professional organizations, do not apply to environmental geology. The nature of three recently started environmental geology journals might yield clues as to the direction of this field.
\end{abstract}

\begin{abstract}
A
s fiscal pressures continue to increase on academic library collections, it becomes critical for collection development librarians to know the scope of the fields that their collections support. Collection development policies are never as current or as informative as they need to be when hard decisions must be made. The recurring nature of serials costs demands a higher level of assurance that funds are being spent wisely. Use studies frequently are employed to quantify and describe local or "normative" demand, as well as to
\end{abstract}

map out the subjects covered in the collections (Kelland and Young 1994).

Citation analysis is one type of use study that often involves data derived from citation indexes produced by the Institute for Scientific Information (ISI) (Kelland and Young 1994). Journal network studies can document the scope of interdisciplinary fields and their changes over time (White and McCain 1989). McCain (1991, 1995) has combined intercitation and cocitation analysis to produce core journal lists in several inter-

LouISE S.ZIPP (lzipp@iastate.edu) is Preservation Reformatting Librarian, Iowa State University, Ames. Manuscript received May 13, 1998; accepted for publication July 23, 1998. 
disciplinary fields, including genetics and biotechnology. To enhance the biotechnology core list, McCain (1995) made two refinements: first, she created a subject heading profile analysis for all journals indexed over a three-year period in Biotechnology Abstracts; and second, she analyzed the relative productivity of the candidate titles with regard to biotechnology. With these approaches, she brought into sharper focus the biotechnology aspects of the existing journal network. Although her efforts are comprehensive, McCain's work includes techniques that can be adapted by practitioners to provide different levels of information on some of the more elusive subjects in which they must build and maintain collections.

\section{Environmental Geology}

Environmental geology has its roots in the environmental movement of the 1960s. From his perspective as director of the Bureau of Economic Geology at the University of Texas, Austin, Flawn (1968) challenged environmental geologists to organize into a professional society to use their knowledge for the public good through the political process. He described environmental geologists (13) as "engineering geologists, economic geologists, hydrologists, and some marine geologists... who are people oriented." By 1970, Flawn had published the first book with a title containing the phrase "environmental geology" (Coates 1985). Geotimes, the newsmagazine of the American Geological Institute (AGI), has reviewed developments in geology annually since 1967. From 1970 through 1991, the review issues included reports on environmental geology as a separate focus of interest.

LaMoreaux (1992), who was the editor of Environmental Geology, predicted that in the near future half the new jobs in science would be created in environmental areas. He noted the new training opportunities offered for professionals in these areas by societies and universities. The creation of degree-granting programs at universities, the founding of environmental institutes, and a growing journal literature were cited as evidence of a maturing infrastructure able to train and support professional scientists in number. Instead of a new professional society with a lobbying role for environmental issues, LaMoreaux recorded the specialization of two major professional societies of geology. The Institute for Environmental Education was founded in 1991 within the Geological Society of America. The American Association of Petroleum Geologists established its Division of Environmental Geosciences in 1992. Environmental geology is still considered to be a growth area within the geosciences, and a substantial percentage of geoscientists employed in 1993 were working in environmental areas (American Geological Institute 1998).

Jackson $(1997,210)$ defined environmental geology as:

a specialty of geology, concerned with Earth processes, Earth resources, and engineering properties of Earth materials and relevant to (1) the protection of human health and natural ecosystems from adverse biochemical and/or geochemical reactions to naturally occurring chemicals or to chemicals and chemical compounds released into the environment by human activities, and (2) the protection [of human] life, safety and well being ... from natural processes ... through land use planning.

Civil engineering, environmental chemistry, geography, regional planning, and environmental medicine, among other fields, also claim parts of these domains.

\section{Statement of Problem}

Identification of a core set of journals helps collection-development librarians build relevant collections. In interdisciplinary fields, this task is problematic but critical to providing balanced representation of growth areas. In this research, a journal network and a list of active serials in environmental geology was developed using intercitation analysis. The use of nonlocal, "normative" data should make the results useful in many academic libraries. The nature of the core titles will serve to further illuminate the scope of this field as it is perceived by librarians. 


\section{METHOD}

To develop the journal network and identify the core titles in this interdisciplinary area, I used the intercitation analysis techniques adapted by McCain (1991, 1995) from work by Servi and Griffith (1980). McCain (1991) contains details about her adaptation and elaboration of the original algorithm, which is a valuable tool because of its flexibility and elegance. The authors demonstrated that the starting point for the analysis need not be core titles but could include titles related to the eventual core list. The algorithm contains several weighting factors that rationalize the effect of heavily cited titles, prolific titles, self-citing titles, and the repeated citing of classic papers. Z-scores are also used to standardize rankings at a critical juncture. By analyzing titles both in the citations they include and in titles in which they are cited, feedback loops can be identified to assist in grouping core journals. The full network reveals itself systematically, and refinements can be used to delineate the portion of interest. Intercitation analysis identifies the components of a journal network and the direction of significant citation flows, but it stops short of assessing the relative strength of those relationships. While McCain used intercitation analysis as one of several tools to develop a comprehensive picture, the technique is valuable to provide baseline information and an overview of the field as a whole.

Intercitation analysis measures journal-to-journal citations and thus the extent to which one title connects with the work published in another journal. I used citing and cited data compiled for 1995 source titles in the ISI database, where environmental science is a featured area of coverage (Garfield 1996). Because the database only includes full bibliometric data on its source titles (i.e., the titles indexed in ISI products), the citing and cited patterns for nonsource journals were not discernable.

\section{Building a Cone List}

To find a starting point, in 1997 I queried eight colleagues who are geoscience li- brarians at major university libraries with large academic geology departments. They were asked to identify the five best environmental geology serials today, although I did not define what I meant by "best." Most respondents submitted more than five titles, and all titles received were included in the first analysis (see table 1). My secondary hypothesis held that the scope of interdisciplinary fields is not necessarily apparent to librarians, even to subject specialists. Thus, I was not surprised at the librarians' nominations or the lack of correlation with the core list I developed through this research. The titles nominated by the librarians were analyzed according to McCain's adaptation of the Servi and Griffith algorithm (McCain 1991, 1995).

Replicating McCain's (1991, 1995) procedure, I examined the citing-cited relationships of journals at three different levels. The nominated titles comprised the first level. A second level of titles constituted those titles that had received a substantial proportion of their overall 1995 citations from titles in the first level. The citing-cited relationships of the second level of titles were examined in the same way to reveal titles at a third level to which they were strongly linked.

At this point I was concerned about the very small potential core list that was developing, so I reviewed the cited-citing data in the journal citation reports (Garfield 1996) for the titles that had already revealed links. I found 30 more journals that might also have had an environmental geology focus, as per Jackson (1997). Those 30 prospective titles were put through the standard analysis, and only one was found to cumulate links. This particular digression was analogous to broadening the starting list of titles, and the results had only a minor effect on the final core list.

Use of the algorithm reveals a network, but refinements are necessary to outline clearly the core titles. McCain (1991, 1995) used cocitation analysis and a subject heading profile analysis coupled with a productivity analysis (1995). I sought a simpler method of refinement. Using McCain's criterion, I had already 
TABLE 1

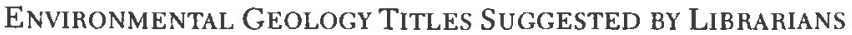

\begin{tabular}{lc}
\hline \hline Title & Frequency \\
\hline Environmental Geology & 5 \\
Ground Water & 4 \\
Engineering Geology & 3 \\
Environmental \& Engineering Geoscience & 3 \\
Global Biogeochemical Cycles & 2 \\
Journal of Contaminant Hydrology & 2 \\
Water Resources Bulletin & 2 \\
Applied Geochemistry & 1 \\
Environmental Geochemistry and Health & 1 \\
Environmental Geosciences & 1 \\
GeoJournal & 1 \\
Geomicrobiology Journal & 1 \\
Hydrogeology Journal & 1 \\
IEEE Transactions on Geoscience and Remote Sensing & 1 \\
Natural Hazards & 1 \\
Northeastern Geology and Environmental Sciences & 1 \\
Water Science and Technology & 1 \\
\hline Note: Nominad tites that Were detemined be & 1 \\
\hline
\end{tabular}

Note: Nominated titles that were determined to be core are shown in bold.

developed a potential core list of 32 titles (out of 66 titles examined) that had at least two links among themselves. After comparing 1995 journal issues of the 32 titles against Jackson's (1997) definition of the field, I eliminated 12 journals in which less than $30 \%$ of articles were on environmental geology topics. The remaining titles comprise the core list for 1995 ( ble 2). Only 5 of those core titles were nominated by geoscience librarians (table 1), and most core titles are primarily identified with other disciplines and specialized fields.

\section{Journal Network and Clusters}

As I examined the journal-to-journal links, a pattern of citing relationships emerged that did not suggest a wholly integrated field. Using Jackson's (1997) definition of environmental geology and my knowledge of the field gained as a former geology librarian, I identified groups, or clusters, of journals that represented aspects of the field. At the scale of inquiry I used in this research, the three clusters I discerned were not themselves linked by substantial citing relationships among their constituent journals.

The Engineering/Materials cluster is centered around International Journal of Rock Mechanics and Mining Sciences it Geomechanics Abstracts, which directly cites, or is cited by, all other titles in that cluster, except Quarterly Journal of Engineering Geology, which is linked only to Engineering Geology. This cluster primarily reflects interest in engineering aspects of the built environment (see table 3). The Geochemistry cluster is very small, with Applied Geochemistry linking the other two titles. While some of the mining pollution literature is published in 
TABLE 2

Core Serial Titles in Environmental Geology

Applied Geochemistry

Bulletin of the Seismological Society of America

Chemical Geology

Engineering Geology

Environmental Pollution

Ground Water

International Journal for Numerical and Analytical Methods in Geomechanics

International Journal of Rock Mechanics and Mining Sciences \& Geomechanics Abstracts

Journal of Contaminant Hydrology

Journal of Environmental Quality

Journal of Geochemical Exploration

Journal of Hydrology

Journal of Soil and Water Conservation

Journal of Water Resources Planning and Management

Mechanics of Materials

Quarterly Journal of Engineering Geology

Transactions of the ASAE

Water, Air, and Soil Pollution

Water Resources Bulletin (now Journal of the American Water Resources Association)

Water Resources Research

these titles, they carry more of the papers on geochemistry of natural systems (see table 3). The Water/Soil cluster is the largest and most variable. Two titles, Journal of Environmental Quality and Water Resources Research, are linked to most of the others in the cluster through citing and cited relationships. This cluster represents interests in ground and surface water resources as well as a pollution and remediation emphasis (Table 3).

An interesting subcluster was identified that linked titles on atmospheric science and biogeochemical cycles through Joumal of Environmental Quality. Biogeochemistry and Global Biogeochemical Cycles are the central titles in this area, which uses the framework of natural cycles (e.g., nutrient, hydrologic) to investigate environmental changes on a broad scale. This perspective is not yet widely recognized as an area of discourse within the domain of environmental geology, and the subcluster was removed from the journal network.

None of the clusters hosted the concerns of policy and planning or of environmental health that Jackson (1997) associated with environmental geology. The extent of these literatures was not investigated here. The absence of policy and planning titles is reasonable, considering the source of the data (Garfield 1996). The absence of titles devoted to environmental health (e.g, Environmental Geochemistry and Health) is not as easily dismissed. Several likely titles were put through the analysis, but the titles with which they were most frequently connected did not directly link to titles at or near the core. This area may have a body of knowledge of interest to environmen- 
TABLE 3

CORE TITLES By Cluster

\author{
Engineering/Materials Cluster \\ Bulletin of the Seismological Society of America \\ Engineering Geology \\ International Journal for Numerical and Analytical Methods in Geomechanics \\ International Journal of Rock Mechanics and Mining Sciences \& Geomechanics \\ Abstracts \\ Mechanics of Materials \\ Quarterly Journal of Engineering Geology \\ Geochemistry Cluster \\ Applied Geochemistry \\ Chemical Geology \\ Journal of Geochemical Exploration \\ Water/Soil Cluster \\ Environmental Pollution \\ Ground Water \\ Journal of Contaminant Hydrology \\ Journal of Environmental Quality \\ Journal of Hydrology \\ Journal of Soil and Water Conservation \\ Journal of Water Resources Planning and Management \\ Transactions of the ASAE \\ Water, Air, and Soil Pollution \\ Water Resources Bulletin \\ Water Resources Research
}

Note: Central titles in bold.

tal geologists but dominated by scholars from other disciplines, such as medicine and chemistry, whose choice of publishing outlets reflects their strongest disciplinary affiliation.

One title is conspicuously absent from the core list. Springer-Verlag's Environmental Geology, nominated by five librarians, was found to only cite itself to a significant degree. Nor was it a major recipient of citations by core titles. Environmental Geology has a bifurcated focus. Techniques and methods articles are intermixed with articles on narrow topics, often geographically set outside the
United States. Thematic issues occasionally appear; in 1995, issues contained conference papers on deep karst systems, which are hydrologic systems in limestone regions identified by sinks and interspersed with abrupt ridges and protruding rocks. Because of the variety in content, citing and cited patterns for a single year might not indicate long-term relationships.

The use of this core journal network must be made in the context of the sources and time period of its development. The ISI indexes as source journals those titles meeting specific criteria; regional titles 
such as Northeastern Geology and Environmental Sciences are excluded. New journals do not typically become source journals for several years until they are well established. While this analysis covers 1995 citations, there are three new journals associated primarily with environmental geology that do not appear on the 1995 source journal list: Environmental \& Engineering Geoscience; Environmental Geosciences; and Hydrogeology Journal. Those of us generating the starting list knew about these titles, but because core lists are snapshots at specific points in time, these journals are not part of this analysis.

\section{Problems of Scope and Funding}

The nature of the core list of serials for environmental geology, as developed in this study, should be both reassuring and troublesome to collection-development librarians. The appearance of established older titles known to be core journals in other subjects suggests that the costs of supporting this literature are already at least in part covered by existing library collection investment. Libraries supporting collections in applied chemistry, hydrology, agronomy, and civil engineering are likely to be supporting good serial collections in environmental geology. Even core titles in an established discipline are subject to cancellation when institutional priorities change. Extra effort must be applied to ensure that journals serving varied readerships are not automatically cancelled when their value to one group diminishes.

A second concern involves the way acquisitions dollars are allocated in academic libraries. Funds tend to be distributed based on the internal structure of the user community. Often, funds are linked to the academic departments or programs and to the level of degrees granted (Budd 1991). Support for centers and institutes may be separate or may be folded into allocations for department support. Another common model in use links funding to an existing mode of organizing knowledge. The Library of Congress classification system and the conspectus developed by the Research Libraries Group are unable to reflect-before the fact- emerging or interdisciplinary interests of the user community because new class numbers are established only after the published literature appears. Allocation by discipline is most effective when each discipline has a commonly understood identity and scope, which is not the case for environmental geology. For these reasons, academic libraries may not be supporting environmental geology coherently even when they do support the core serial literature through the more established related disciplines.

\section{INTERDISCIPLINARITY}

The nature of an interdisciplinary area determines its visibility, and to some extent, its legitimacy to library-collection builders. Klein (1990, 1996) discussed disciplines and the growth of interdisciplinary fields. She listed a series of achievements by which $(1995,35-36)$ "interdisciplinary fields make marks in cultural space." They include:

- an adequate number of workers with shared interests and academic and research programs of sufficient scale;

- adequate communication infrastructure along with "economic and symbolic capital";

- formalization of research activities and their infrastructure;

- power and control in university and faculty governance matters; and

- the appearance of a scholarly body of knowledge, coupled with the ability to synthesize and generate knowledge across disciplines.

According to Klein, environmental studies is an interdisciplinary field that has not developed into a discipline, although it may have some of the trappings of disciplinarity. As federal funds for academic research diminished in the 1980s, environmental studies programs strengthened their affiliation with the parent departments, and the resulting identities have become quite variable among institutions. Klein (1996) argues that environmental studies has not devel- 
TABLE 4

NEW EnVironmental Geology Journals

Environmental \& Engineering Geoscience, from 1995, sponsored by the Association of Enginering Geologists and the Geological Society of America

Encironmental Geosciences, from 1995, (1994 as Journal), sponsored by the Americal Association of Petroleum Geologists Division of Environmental Geosciences

Hydrogeology Journal, from 1995, (1992-94 as Applied hydrogeology), sponsored by the Hydrogeology Division of the Geological Society of America and the International Association of Hydrogeologists

oped a strong community, and synthesis and integration of knowledge has not yet been achieved.

Environmental geology also does not meet accepted criteria for disciplinary status. Writing about materials science, Roy (1979) stated that disciplinary recognition would require the founding of 12 to $20 \mathrm{uni}$ versity departments. The American Geological Institute (1996) reports no departments of environmental geology in United States colleges or universities, although there were 134 academic departments with Master's degrees in the environmental geosciences. Environmental geology is an identifiable specialty or segment of focus in the two major U.S. professional organizations in geology: the American Association of Petroleum Geologists and the Geological Society of America. The interests of this community are also served by other professional organizations in water resources, geochemistry, engineering, agronomy and science education. Finally, this intercitation analysis of the 1995 literature has shown that journals publishing research in environmental geology tend to be more closely associated with older, established fields.

If not as a discipline, how does environmental geology present itself to collection development librarians? Its boundaries are not always visible, although the core areas of surface and groundwater quality are easily identifiable across institutional contexts. Created to deal with specific problems at the Earth's surface that are caused or exacerbated by human action, this interdisciplinary field is perhaps better approached as a specialty within the larger field of environmental science or geology, at least in settings where those broader fields are locally defined and legitimized. Librarians must continue to depend on researchers' expressions of needs as well as their own knowledge of new journals, new courses, new faculty and their research interests, and the activities of professional societies.

The three recently started journals mentioned above may hold a primary key to how this interdisciplinary field develops in the future (see table 4). All three titles are sponsored by professional societies. If the journals serve to reinforce the existing subdisciplines of geology, there is even less evidence for the movement of environmental geology toward achievement of disciplinary status (Swoboda 1979). According to Klein (1996), interdisciplinary journals serve particular functions, including coverage of problem-focused fields and the advancement of hybrid fields and hybrid methods. These journals are particularly useful for promoting communication among a dispersed community and for offering publication opportunities for research that is radical or different. Despite these characteristics, she suggests (26-27) that a longitudinal examination of such journals would show more "shifts in orientation and interest claims" rather than "sustained lines of synthesis." One way for librarians to meet the challenge of building relevant library collections is to track changes in the body of knowledge particular to environmental geology. 


\section{CONCLUSION}

To the extent that we can recognize the distinctions between interdisciplinary fields and disciplines, collection-development librarians can track the status of environmental geology as a formalizing, interdisciplinary field of knowledge. Klein (1996) suggested that problem-driven areas of discourse promote greater fragmentation in the community of scholars. A known set of core journals, based on nonlocal data, provides a broad-scale context for visualizing the boundaries of an interdisciplinary field. From this perspective, collection-development librarians can continue to focus on the specific problem and question areas relevant to their own library clientele. These areas will include knowledge sites where interdisciplinary boundaries are breached to create new knowledge. The discourse on biogeochemical cycles is a knowledge site where we might detect the early development of a new discipline and start building library collections to support its community.

Librarians have traditionally focused on the manifestations of disciplines as decisions are made about library collections. Identification of a set of core journals is a useful point of departure for collection development activities. An understanding of the disciplinary context can help to make even better use of scarce resources.

\section{Works CITED}

American Geological Institute. 1996. Academic departments with environmental geoscience programs. Online. Available: http://www.agiweb.org/agi/environment/ departmentlist.html. 5 May

- 1998. Geoscientists by discipline and sector. Online. Available: http://www. agiweb.org/career/geosec.html. 5 May.

Budd, John M. 1991. Allocation formulas in the literature: A review. Library acquisitions: Practice of theory 15: 95-107.

Flawn, Peter T. 1968. The environmental geol- ogist and the body politic. Geotimes 13, no. 6: 13-14.

Garfield, Eugene. 1996. SCI journal citation reports: A bibliometric analysis of science journals in the ISI database. Philadelphia: Institute for Scientific Information.

Jackson, Julia A. 1997. Glossary of geology. 4th ed. Alexandria, Va: : American Geological Institute.

Kelland, John L. and Arthur P. Young. 1994. Citation as a form of library use. Collection management 19, no. 1/2: 81-100.

Klein, Julie T. 1990. Interdisciplinarity: History, theory, and practice. Detroit: Wayne State University Press.

- 1996. Crossing boundaries: Knowledge, disciplinarities, and interdisciplinarities. Charlottesville: University Press of Virginia.

LaMoreaux, Philip E. 1992. Action on the environmental front. Geotimes 37, no. 11: 18-20.

McCain, Katherine IV. 1991. Core journal networks and cocitation maps: New bibliometric tools for serials research and management. Library quarterly 61: 311-36.

. 1995. Biotechnology in context: A database filtering approach to identifying core and productive non-core journals supporting multidisciplinary R \& D. Journal of the American Society for Information Science 46: 306-17.

Roy, Rustum. 1979. Interdisciplinary science on campus: The elusive dream. In Interdisciplinarity and higher education, ed. Joseph J. Kockelmans. University Park: Pennsylvania State University Press.

Servi, Patricia N. and Belver C. Griffith. 1980. A method for partitioning the journal literature. Journal of the American Society for Information Science 31: 36-40.

Swoboda, Wolfram W. 1979. Disciplines and interdisciplinarity: A historical perspective. In Interdisciplinarity and higher education, ed. Joseph J. Kockelmans. University Park: Pennsylvania State University Press.

White, Howard D. and Katherine W. McCain. 1989. Bibliometrics. Annual review of information science and technology 24 : 119-86. 